\title{
Frequency of complications and the effects of pneumococcal vaccination in young children with acute respiratory tract infection
}

\author{
Juliana R. Oliveira a,*, Maiara L. Bouzas ${ }^{a}$, Maria-Regina A. Cardoso ${ }^{b}$, Aldina Barral ${ }^{\mathrm{a}, \mathrm{c}, \mathrm{e}}$, \\ Cristiana Nascimento-Carvalho ${ }^{\mathrm{a}, \mathrm{d}}$, the Acute Respiratory Infection and Wheeze Study \\ Group Phase I and II $^{\mathrm{d}}$
}

\footnotetext{
a Postgraduate Program in Health Sciences, Federal University of Bahia School of Medicine, Salvador, Brazil

${ }^{b}$ Department of Epidemiology, São Paulo University School of Public Health, São Paulo, Brazil

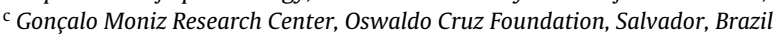

d Department of Pediatrics, Federal University of Bahia School of Medicine, Salvador, Brazil

e Department of Pathology, Federal University of Bahia School of Medicine, Salvador, Brazil
}

\section{A R T I C L E I N F O}

\section{Article history:}

Received 15 December 2015

Received in revised form 5 April 2016

Accepted 6 April 2016

Available online 18 April 2016

\section{Keywords:}

Pneumococcal conjugate vaccine

Children

Common cold

Viruses

\begin{abstract}
A B S T R A C T
Background: Acute respiratory infection (ARI) is the most frequent reason for children being seen by doctors worldwide. We aimed to estimate the frequency of complications in children aged 6-23 months during ARI episode and to evaluate risk factors present on recruitment associated with complications after the universal implementation of pneumococcal vaccine (PCV10) in our region.

Methods: This prospective cohort enrolled children who had shown ARI for up to 7 days and who were subsequently followed up 14-21 days after, in Salvador, Brazil. Data on recruitment were registered. The vaccine card was personally checked. Complication was defined when hospitalization, pneumonia or acute otitis media (AOM) were informed during the follow-up visit. Pneumonia and AOM were diagnosed by a doctor. Multiple logistic regression analysis was performed.

Results: Of 576 children, 422 (73\%) returned and 79 (19\%; 95\%CI: 15-23\%) had complications. The mean interval between admission and follow-up was $23 \pm 13$ days. Pneumonia $(n=47 ; 11 \%)$, hospitalization $(n=28 ; 7 \%)$, and AOM $(n=17 ; 4 \%)$ were reported. Most of the patients presented one complication $(n=66 ; 84 \%)$ followed by two $(n=13 ; 16 \%)$. Report of fever (92\% versus 79\%; OR [95\%CI]: 2.90 [1.18-7.14]), bird at home (24\% versus 14\%; OR [95\%CI]: 2.13 [1.07-4.26]), ronchi (48\% versus 36\%; OR [95\%CI]: 2.06 [1.16-3.67]) or crackles (17\% versus 7\%; OR [95\%CI]: 2.36 [1.04-5.38]) on auscultation were directly associated with complications whereas PCV10 (59\% versus 75\%; OR [95\%CI]: 0.46 [0.26-0.82]) was inversely associated. Bird at home (OR [95\%CI]: 5.80 [1.73-19.38]) and ronchi (OR [95\%CI]: 6.39 [1.96-20.85]) were associated with AOM; PCV10 was inversely associated with AOM (OR [95\%CI]: 0.16 [0.05-0.52]). Crackles were associated with pneumonia (OR [95\%CI]: 2.55 [1.01-6.40]).

Conclusions: One fifth of the children presented complications. PCV10 was independently associated with lower odds of development of AOM. Bird at home and ronchi are risk factors of otitis. Crackles are associated with pneumonia.
\end{abstract}

C 2016 Published by Elsevier Ltd

\section{Introduction}

One of the most common problems that affect children within their first years of life is the occurrence of acute respiratory infections (ARI). It has been reported an adjusted frequency of 6.2 ARI

\footnotetext{
* Corresponding author at: Largo do Terreiro de Jesus, s/n, Centro Histórico, CEP 40025-010 Salvador, Brazil. Tel.: +55 71 999179949; fax: +55 7132835567 .

E-mail address: juliamar1@ig.com.br (J.R. Oliveira).
}

episodes per child-year among children aged under three years [1] ARI has been recognized as the main reason for families seeking pediatric assistance [2].

ARI symptoms generally include runny nose, nasal blockage, low-grade fever, cough and the episode can evolve to severe complications, particularly in young children $[1,3]$. These complications are mainly acute otitis media (AOM), pneumonia, and hospitalization [4-6]. Heikkinen et al. reported the highest frequency for AOM (39.7\%), followed by pneumonia (2.4\%) and hospitalization $(0.8 \%)$ in children after an influenza infection [7]. In general, 
malnutrition, inadequate breast feeding and poor immunization have been indicated as the main risk factors involved in the occurrence of complications due to ARI [8]. Pneumococcal infection has been considered as potentially key in the occurrence of ARI complications [9]. There is an increasing frequency of pneumococcal colonization during clinical ARI and the physical changes produced by viral infection in the nasal passages facilitate the isolation or acquisition of pneumococci [9].

We aimed to estimate the frequency of complications in children aged between 6 and 23 months during an ARI episode. We further evaluated risk factors present on recruitment associated with complications after the universal implementation of pneumococcal vaccine (PCV10) in our region.

\section{Methods}

Our prospective cohort evaluated children aged from 6 to 23 months with symptoms of ARI between September 2009 and October 2013 at an Emergency Department in Salvador, Northeastern Brazil. Children with ARI defined as report of either fever, sneeze, running nose, nasal blockage, or cough for up to seven days were evaluated in the study. Children transferred from other hospitals or reporting previous episode of wheeze were excluded. Parents or legal guardians were invited to sign the written informed consent and, for the eligible children, they were invited to answer a standardized questionnaire.

The questionnaire contained data on the present illness, obstetric, neonatal, family morbidities, as well as the child's lifestyle, and physical examination performed by the emergency pediatrician. Between 14 and 28 days after the study's admission, children returned for a follow up visit and parents or legal guardians answered a questionnaire about the ARI evolution. Complications comprised the following events: hospitalization, pneumonia and AOM. Pneumonia was diagnosed when the child presented cough or fever along with difficulty breathing AND pulmonary infiltrate, consolidation, or pleural effusion in the chest radiograph. AOM was diagnosed when the child presented earache along with tympanic alterations found by otoscopy (bulging position, decreased or absent mobility, abnormal color or opacity, or air-fluid interfaces PLUS distinct erythematous patches or streaks or increased vascularity). Pneumonia and AOM were diagnosed by a doctor.

Nutritional status evaluation was performed by using the software Anthro, version 3.2.2; severe malnutrition, malnutrition, overweight and obesity were defined as $z$-score for weight-forheight index, respectively, lower than -3 , lower than -2 , higher than 2, higher than 3, by using the World Health Organization (WHO) standard [10]. Fever was defined as axillary temperature higher than $37.4^{\circ} \mathrm{C}[11]$, and tachypnea as respiratory rate (RR) equal to or higher than 50 breaths/min in children aged 6-11 months and RR equal to or higher than 40 breaths/minute in children from 12 months of age onwards [12].

Pneumococcal vaccine (PCV10: Synflorix, GlaxoSmithKline Biologicals, Rixensart, Belgium) was introduced in Salvador, Brazil, in July 2010 for children aged $<2$ years [13]. Every child included in the study who could have received PCV10 had the vaccine card checked personally by one of the researchers upon recruitment.

Data were entered into Epi Info version 6.04. Data analyses were performed using STATA version 11.0. Descriptive statistics with their $95 \%$ confidence intervals $(95 \% \mathrm{CI}$ ) were calculated. Independent variables that appeared to be significant in bivariate analyses were firstly included in a robust Poisson model. All the other independent variables and possible interactions were also assessed before the final model to estimate their independent effects on development of complications. The study was approved by the Ethics Committee from the Federal University of Bahia.

\section{Results}

Among 1154 evaluated children, 504 (43.7\%) reported previous episode of wheeze, 11 (1\%) came from other hospitals and $63(5.4 \%)$ did not consent. Thus, 576 (49.9\%) children were recruited, out of which $422(73.3 \%)$ returned for reevaluation and were included in this study group. Table 1 in the supplementary material shows the comparison of children who returned with children who did not return.

The baseline characteristics of the study group $(n=422)$ are described in Table 1 . The median age was 10 months (mean $11.4 \pm 4.5), 278$ (65.9\%) were younger than 1 year, 167 (39.6\%) were in the range of 6-9 months of age, 206 (48.8\%) were males, and 407 (96.4\%) were born in Salvador. Most children 391 (92.6\%) had been breastfed, and 207 (49\%) were still being breastfed at the time of recruitment. The vaccination card could be checked for $384(91 \%)$ children out of which 277 (72.1\%) and 168 (43.8\%) received PCV10 or influenza vaccine, respectively. The numbers of PCV10 doses that had been given were: 1 dose (36 patients; $13.0 \%$ ), 2 doses (96 patients; 34.7\%), 3 doses (116 patients; 41.9\%), 4 doses (29 patients; $10.4 \%$ ). Presence of environmental factors at home was reported by informants: smokers in the household ( $n=80 ; 19 \%)$, cockroaches 278 (65.9\%), insects 271 (64.2\%), dust 233 (55.2\%), mold 139 (32.9\%), rats 108 (25.6\%), dogs 93 (22\%), bird 68 (16.1\%), cats $27(6.4 \%)$ and chicken $15(3.6 \%)$. On physical examination, fever 161 (39.1\%), ronchi 162 (38.4\%) and tachypnea 99 (23.8\%) were the most frequent findings.

The mean interval between admission and the follow-up visit was $23 \pm 13$ days, median [interquartile range]: 19 [15-27] days. Overall, complications were detected in 79 (19\%; 95\% CI: 15-23\%) patients and this frequency was similar among children aged under 1 year or 1 year and above (17.3\% vs. $21.5 \% ; p=0.3)$. Pneumonia ( $n=47 ; 11.1 \%)$, hospitalization $(n=28 ; 6.6 \%)$ and AOM $(n=17 ; 4.0 \%)$ were reported. Most of the patients presented one complication ( $n=354 ; 84 \%)$ followed by two $(n=67 ; 16 \%)$. Overall, 28 patients were hospitalized, 10 with pneumonia and 3 with AOM; the other 15 had other respiratory discomfort.

Tables 2-4 depict the comparison of medical history, environmental factors and clinical presentation of children with or without complications. Differences were significant in bivariate analysis when report of fever, report of wheeze, duration of hoarseness, use of PCV10, chicken or bird at home, ronchi or crackles at physical examination upon recruitment, were all assessed. Table 5 presents the multivariate analysis of factors associated with complications in bivariate analysis. Directly independent association was found between history of fever (OR [95\%CI]: 3.30 [1.38-7.89]), bird at home (OR [95\%CI]: 1.90 [1.04-3.45]), ronchi (OR [95\%CI]: 1.64 [0.99-2.68]) or crackles (OR [95\%CI]: 2.62 [1.27-5.41]) at physical examination and complications. Conversely, use of PCV10 was inversely associated with complications. We further assessed the independent association of factors on recruitment in regard to each one of the complications: bird at home (OR [95\%CI]: 5.80 [1.73-19.38]) and ronchi (OR [95\%CI]: 6.39 [1.96-20.85]) were associated with AOM; PCV10 was inversely associated with AOM (OR [95\%CI]: 0.16 [0.05-0.52]). Crackles were associated with pneumonia (OR [95\%CI]: 2.55 [1.01-6.40]).

\section{Discussion}

Our study showed that development of complications during an ARI episode is common among young children as one fifth of them had complications. Pneumonia was the most frequent complication. An environmental factor (bird at home) was an independent risk factor of AOM. On the other hand, PCV10 was independently associated with lower odds of development of AOM. Auscultatory 
Table 1

Baseline characteristics of 422 children with acute respiratory infection on recruitment.

\begin{tabular}{|c|c|c|}
\hline Characteristics & $n(\%)$ & Duration mean $\pm S D$, min-max \\
\hline \multicolumn{3}{|l|}{ History } \\
\hline Cough & $369(87.4)$ & $3.6 \pm 1.8,1-7^{\mathrm{b}}$ \\
\hline Running nose & $359(85.1)$ & $3.6 \pm 1.7,1-7^{b}$ \\
\hline Fever & $342 / 421(81.2)^{a}$ & $2.9 \pm 1.5,1-7^{b}$ \\
\hline Sneeze & $331(78.4)$ & $3.5 \pm 1.7,1-7^{b}$ \\
\hline Wheeze & $168(39.8)$ & $2.5 \pm 1.6,1-7^{b}$ \\
\hline Hoarseness & $128(30.3)$ & $2.8 \pm 1.6,1-7^{b}$ \\
\hline Dyspnea & $115(27.3)$ & $2.8 \pm 1.6,1-7^{b}$ \\
\hline Vomiting & $54(12.8)$ & $2.0 \pm 1.5,1-7^{b}$ \\
\hline Earache & $32 / 420(7.6))^{a}$ & $2(1,4), 1-7^{b, c}$ \\
\hline Thoracic retraction & $44(10.4)$ & $2.6 \pm 1.9,1-7^{b}$ \\
\hline \multicolumn{3}{|l|}{ Obstetric } \\
\hline Low birth weight & $54 / 406(13.3)^{a}$ & \\
\hline Early respiratory distress & $25 / 420(6.0)^{a}$ & \\
\hline Prematurity & $47(11.1)$ & \\
\hline Neonatal oxygen & $22 / 419(5.3)^{a}$ & $3.0(1,3), 1-60^{b, c}$ \\
\hline Mechanical ventilator & $10 / 420(2.4)^{a}$ & \\
\hline Smoking mother during pregnancy & $19(4.5)$ & \\
\hline Smoking mother nowadays & $26(6.2)$ & \\
\hline Flu vacine during pregnancy & $255 / 396(64.4)^{\mathrm{a}}$ & \\
\hline \multicolumn{3}{|l|}{ Vaccination } \\
\hline Pneumococcal (PCV10) & $277 / 384(72.1 \%)^{\mathrm{a}}$ & \\
\hline Influenza & $168 / 384(43.8 \%)^{\underline{a}}$ & \\
\hline \multicolumn{3}{|l|}{ Breastfeeding } \\
\hline Exclusive & $353 / 420(84.0)^{\mathrm{a}, \mathrm{d}}$ & $4.7 \pm 1.9,0.1-13^{\mathrm{d}, \mathrm{e}}$ \\
\hline Mixed & $253 / 421(60.1)^{\mathrm{a}, \mathrm{d}}$ & $8.8 \pm 4.2,0.5-21^{\mathrm{d}, \mathrm{e}}$ \\
\hline \multicolumn{3}{|l|}{ Family history } \\
\hline Rhinitis & $247 / 421(58.7)^{a}-$ & \\
\hline Asthma & $121 / 420(28.8)^{a}$ & \\
\hline Skin allergy & $85 / 421(20.2)^{a}$ & \\
\hline \multicolumn{3}{|l|}{ Infant lifestyle } \\
\hline Shared bed & $311(73.7)$ & \\
\hline Smokers at home & $80(19)$ & \\
\hline Absence of ventilation at home & $138(32.7)$ & \\
\hline Chicken at home & $15(3.6)$ & \\
\hline Bird at home & $68(16.1)$ & \\
\hline \multicolumn{3}{|l|}{ Physical examination } \\
\hline Severe malnutrition & $1(0.2)$ & \\
\hline Malnutrition & $4(0.9)$ & \\
\hline Overweight & $33(7.8)$ & \\
\hline Obesity & $9(2.1)$ & \\
\hline Tachypnea & $99 / 416(23.8)^{a}$ & \\
\hline Fever & $161 / 412(39.1)^{a}-$ & \\
\hline Ronchi & $162(38.4)$ & \\
\hline Wheezing & $68(16.1)$ & \\
\hline Crackles & $37(8.8)$ & \\
\hline
\end{tabular}

a The denominator was not 422 because there was missing information.

b Duration in days.

c Median (25th percentile, 75th percentile), min-max.

d Mixed breastfeeding was informed for 1 child but the informant did not know if this child had been exclusively breastfed.

e Duration in months.

findings (ronchi and crackles) were independently associated with AOM or pneumonia, respectively.

Although most ARI in children are self-limited, complications can happen. Young children ( $<2$ years of age) are more susceptible to complications [6]. In our study we found complications in $19 \%$ of the patients evaluated, a frequency close to the one found in a French Pediatric Emergency Department (12\%) where children younger than 36 months were evaluated [14]. Herein, the most frequently observed complication was pneumonia $(11.1 \%)$ followed by hospitalization (6.6\%) and AOM (4.0\%). In a longitudinal study in children $<2$ years conducted in Bangladesh, out of 1322 episodes of ARI, pneumonia (29\%), AOM (2\%) and hospitalization (0.3\%) were reported [15]. The difference in the frequency of pneumonia and hospitalization between the two studies may be explained by differences in the management of ARI cases in these two countries (Brazil and Bangladesh). Pneumonia was diagnosed only on clinical grounds in Bangladesh whereas it is usually confirmed by chest radiograph in Brazil [16]. Diagnosis of pneumonia based solely on clinical grounds overestimates pneumonia diagnosis [17]. On the other hand, admission to hospital in Bangladesh is more difficult than in Brazil due to limited number of hospital beds [18].

Auscultatory findings such as ronchi and crackles can be regarded as warning signs for complications. As such, close followup must be provided to patients showing these signs upon admission, in order to detect complications as soon as possible. Ronchi on pulmonary auscultation is a sign of secretion in the airways and had association with AOM in our study. It has been shown that transient negative middle ear pressure occurs in two thirds of uncomplicated colds in healthy children [19], who have secretion in the airways. This negative pressure may facilitate secondary AOM [19].

Bird at home was a risk factor of AOM. Allergen exposure may occur from contact with bird feathers or droppings. In a study conducted among school-age children to determine whether exposure to pets plays a significant role in the development of allergic diseases, rhinitis was more common among children who had a pet at home, including poultry, other birds, and cats in comparison with children living in homes without pets $(33.3 \%$ vs. $18.0 \%, p<0.001$ ) 
Table 2

Comparison of medical history variables among children with acute respiratory infection with or without development of complications during evolution.

\begin{tabular}{|c|c|c|c|}
\hline \multirow[t]{2}{*}{ Characteristics } & \multicolumn{2}{|l|}{ Complications } & \multirow[t]{2}{*}{$p$} \\
\hline & Yes $(n=79)$ & No $(n=343)$ & \\
\hline Age (months, mean $\pm \mathrm{SD}$ ) & $11.4 \pm 4.6$ & $10.7 \pm 4.4$ & 0.2 \\
\hline \multicolumn{4}{|l|}{ History } \\
\hline Cough & $70(88.6 \%)$ & $299(87.2 \%)$ & 0.73 \\
\hline Duration of cough (days, mean $\pm S D$ ) & $3.7 \pm 1.7$ & $3.6 \pm 1.8$ & 0.80 \\
\hline Running nose & $72(91.1 \%)$ & $287(83.7 \%)$ & 0.09 \\
\hline Duration of running nose (days, mean $\pm S D$ ) & $3.8 \pm 1.6$ & $3.5 \pm 1.7$ & 0.18 \\
\hline Fever & $73(92.4 \%)$ & $269 / 342(78.7 \%)^{\mathrm{a}}$ & 0.005 \\
\hline Duration of fever (days, mean \pm SD) & $3.1 \pm 1.6$ & $2.8 \pm 1.5$ & 0.11 \\
\hline Sneeze & $63(79.7 \%)$ & $268(78.1 \%)$ & 0.75 \\
\hline Duration of sneeze (days, mean $\pm S D$ ) & $3.7 \pm 1.8$ & $3.5 \pm 1.7$ & 0.40 \\
\hline Wheeze & $40(50.6 \%)$ & $128(37.3 \%)$ & 0.03 \\
\hline Duration of wheeze (days, mean \pm SD) & $2.8 \pm 1.6$ & $2.4 \pm 1.6$ & 0.16 \\
\hline Hoarseness & $24(30.4 \%)$ & $104(30.3 \%)$ & 1.00 \\
\hline Duration of hoarseness (days, mean \pm SD) & $2.0 \pm 1.3$ & $2.9 \pm 1.6$ & 0.01 \\
\hline Dyspnea & $26(32.9 \%)$ & $89(25.9 \%)$ & 0.21 \\
\hline Duration of dyspnea (days, mean $\pm S D$ ) & $3.1 \pm 1.8$ & $2.8 \pm 1.6$ & 0.41 \\
\hline Vomiting & $10(12.7 \%)$ & $44(12.8 \%)$ & 1.00 \\
\hline Duration of vomiting (days, mean $\pm S D$ ) & $2.7 \pm 1.9$ & $1.9 \pm 1.3$ & 0.13 \\
\hline Earache & $4 / 78(5.1 \%)^{b}$ & $28 / 342(8.2 \%)^{a}$ & 0.40 \\
\hline Duration of earache (days, median (IQR)) & $2.5(2-3.8)$ & $2.0(1-4.0)$ & 0.60 \\
\hline Thoracic retraction & $10(12.7 \%)$ & $34(9.9 \%)$ & 0.50 \\
\hline Duration of thoracic retraction (days, mean $\pm S D$ ) & $2.7 \pm 2.0$ & $2.5 \pm 1.9$ & 0.80 \\
\hline \multicolumn{4}{|l|}{ Obstetric } \\
\hline Low birth weight & $7 / 73(9.6 \%)^{b}$ & $47 / 333(14.1 \%)^{\mathrm{a}}$ & 0.30 \\
\hline Early respiratory distress & $7(8.9 \%)$ & $18 / 341(5.3 \%)^{\mathrm{a}}$ & 0.29 \\
\hline Prematurity & $7(8.9 \%)$ & $40(11.7 \%)$ & 0.50 \\
\hline Neonatal oxygen & $5(6.3 \%)$ & $17 / 340(5.0 \%)^{\mathrm{a}}$ & 0.60 \\
\hline Duration of neonatal oxygen (days, median (IQR)) & $3.0(1.5-5)$ & $3.0(1-3)$ & 0.83 \\
\hline Mechanical ventilator & $2(2.5 \%)$ & $8 / 341(2.3 \%)^{\mathrm{a}}$ & 1.00 \\
\hline Smoking mother during pregnancy & $2(2.5 \%)$ & $17(5.0 \%)$ & 0.55 \\
\hline Smoking mother during nowadays & $2(2.5 \%)$ & $24(7.0 \%)$ & 0.20 \\
\hline Flu vaccine during pregnancy & $44 / 77(57.1 \%)^{b}$ & $211 / 319(66.1 \%)^{\mathrm{a}}$ & $\begin{array}{c}0.14 \\
\text { Vaccination }\end{array}$ \\
\hline Pneumococcal (PCV10) & $43 / 73(58.9 \%)^{\mathrm{b}}$ & $234 / 311(75.2 \%)^{\mathrm{a}}$ & 0.005 \\
\hline Influenza & $30 / 73(44.1 \%)^{b}$ & $138 / 311(44.4 \%)^{\mathrm{a}}$ & 0.61 \\
\hline \multicolumn{4}{|l|}{ Breastfeeding } \\
\hline Exclusive & $69(87.3 \%)$ & $284 / 341(83.3 \%)^{\mathrm{a}}$ & 0.38 \\
\hline Duration of breastfeeding exclusive (months, mean \pm SD) & $4.9 \pm 2.0$ & $4.6 \pm 1.9$ & 0.23 \\
\hline Mixed & $46(58.2 \%)$ & $207 / 342(60.5 \%)^{\mathrm{a}}$ & 0.70 \\
\hline Duration of breastfeeding mixed (months, mean \pm SD) & $9.1 \pm 4.8$ & $8.7 \pm 4.1$ & 0.70 \\
\hline
\end{tabular}

a The denominator was not 343 because there was missing information.

b The denominator was not 79 because there was missing information.

[20]. Patients with rhinitis have nasal inflammation, and Eustachian tube dysfunction, which lead to increased negative pressure in the middle ear and improper ventilation, with enhanced nasal protein transudation. As a result, respiratory secretions are produced and can lead to AOM [21].

The universal implementation of pneumococcal conjugate vaccines has been a major public health intervention to prevent pneumococcal disease. In our country, evidence has been provided that the introduction of PCV10 in the routine immunization program has effectively lowered rates of hospitalization due to pneumonia among children [22]. As there is increasing frequency of pneumococcal colonization during clinical ARI [9], the use of PCV

Table 3

Comparison of environmental factors among children with acute respiratory infection with or without development of complications during evolution.

\begin{tabular}{lccc}
\hline \multirow{2}{*}{ Evironmental factors } & \multicolumn{2}{c}{ Complications } & \multirow{2}{*}{$p$} \\
\cline { 2 - 3 } & Yes $(n=79)$ & No $(n=343)$ & \\
\hline Shared bed & $58(73.4 \%)$ & $253(73.8 \%)$ & 1.00 \\
Smokers at home & $17(21.5 \%)$ & $63(18.4 \%)$ & 0.52 \\
Absence of ventilation at home & $26(32.9 \%)$ & $112(32.7 \%)$ & 1.00 \\
Chicken at home & $7(8.9 \%)$ & $8(2.3 \%)$ & 0.01 \\
Bird at home & $19(24.1 \%)$ & $49(14.3 \%)$ & 0.03 \\
\hline
\end{tabular}

probably impacts on the frequency of such colonization. For those vaccinated, the risk of hospitalization due to influenza-associated pneumonia has decreased to approximately half the risk among children who had not received this vaccine [23]. Herein, PCV10 did not protect children against pneumonia. The vast majority of our

Table 4

Comparison of clinical presentation factors among children with acute respiratory infection with or without development of complications during evolution.

\begin{tabular}{llll}
\hline \multirow{2}{*}{ Clinical presentation } & \multicolumn{2}{l}{ Complications } & \multirow{2}{*}{$p$} \\
\cline { 2 - 3 } & Yes $(n=79)$ & No $(n=343)$ & \\
\hline Severe malnutrition & $1(1.3 \%)$ & 0 & 0.2 \\
Malnutrition $^{\mathrm{c}}$ & $1 / 78(1.3 \%)$ & $3(0.9 \%)$ & 0.6 \\
Overweight $^{\mathrm{d}}$ & $7 / 76(9.2 \%)$ & $26 / 337(7.7 \%)$ & 0.7 \\
Obesity $_{\text {Tachypnea }}$ & $3(3.8 \%)$ & $6(1.7 \%)$ & 0.4 \\
Fever & $18(22.8 \%)$ & $81 / 337(24.0 \%)^{\mathrm{a}}$ & 0.81 \\
Ronchi & $35 / 77(45.5 \%)^{\mathrm{b}}$ & $126 / 335(37.6 \%)^{\mathrm{a}}$ & 0.20 \\
Wheezing & $38(48.1 \%)$ & $124(36.2 \%)$ & 0.049 \\
Crackles & $18(22.8 \%)$ & $50(14.6 \%)$ & 0.07 \\
\end{tabular}

a The denominator was not 343 because there was missing information.

b The denominator was not 79 because there was missing information.

c The patient with severe malnutrition was excluded from this analysis.

d The patients with obesity were excluded from this analysis. 
Table 5

Multivariate analysis of factors associated with complications among 384 children with acute respiratory infection.

\begin{tabular}{|c|c|c|c|c|}
\hline \multirow[t]{2}{*}{ Factors } & \multicolumn{2}{|l|}{ Bivariate analysis } & \multicolumn{2}{|l|}{ Multivariate analysis } \\
\hline & Unadjusted OR (95\% CI) & $p$ & Adjusted OR (95\% CI) & $p$ \\
\hline Male gender & $1.33(0.81-2.18)$ & 0.3 & $1.58(0.91-2.73)$ & 0.1 \\
\hline Age & $1(0.99-1.00)$ & 0.3 & $0.99(0.99-1.00)$ & 0.7 \\
\hline History of fever & $3.30(1.38-7.89)$ & 0.007 & $2.90(1.18-7.14)$ & 0.02 \\
\hline History of wheeze & $1.72(1.05-2.82)$ & 0.03 & $1.11(0.62-1.97)$ & 0.7 \\
\hline Duration of hoarseness & $0.65(0.45-0.93)$ & 0.02 & $0.88(0.73-1.05)$ & 0.2 \\
\hline Pneumococcal vaccination (PCV10) & $0.47(0.28-0.80)$ & 0.006 & $0.46(0.26-0.82)$ & 0.009 \\
\hline Chicken at home & $4.07(1.43-11.58)$ & 0.008 & $2.30(0.74-7.18)$ & 0.15 \\
\hline Bird at home & $1.90(1.04-3.45)$ & 0.04 & $2.13(1.07-4.26)$ & 0.03 \\
\hline Ronchi & $1.64(0.99-2.68)$ & 0.05 & $2.06(1.16-3.67)$ & 0.01 \\
\hline Crackles & $2.62(1.27-5.41)$ & 0.009 & $2.36(1.04-5.38)$ & 0.04 \\
\hline
\end{tabular}

cases were not hospitalized. That said, it is possible to infer that PCV10 protects against more severe cases of pneumonia.

A recent Cochrane Database Systematic Review about efficacy of pneumococcal conjugate vaccines for preventing pneumonia reported modest beneficial effects in healthy infants with a low baseline risk of AOM gained from the licensed 7-valent CRM197-PCV7 [24]. From an internationally recognized transparent Excel-based model, it was possible to predict that PCV10 will decrease morbidity by reducing the outpatient care due to AOM in Georgia [25]. In the present study, PCV10 was inversely associated with complications during ARI. To the best of the authors' knowledge, this is the first cohort to demonstrate this finding. Reduction in the frequency of tympanostomy tube placements in children attributable to PCV10 has been newly reported [26].

This study has limitations. Approximately one quarter (26.7\%) of the recruited patients did not return for the follow-up evaluation. However, the only difference found between patients who returned or not for follow-up was the higher frequency of vomiting among those who did not return (Table 1 in the Supplementary material). That means, none of the differences found between children who did or did not have complications were also detected among the patients excluded due to lost follow-up. Another limitation is that not all followed-up patients had the vaccination card available to be checked. However, this loss was less than $10 \%$, as $384(90.1 \%)$ had the vaccination card with them. Moreover, statistical differences were found in the multivariate analysis despite the fact that the sample size had been decreased due to absence of information retrieved from the vaccination card. Furthermore, no result from laboratory test to investigate the causative agents was available.

\section{Conclusion}

We conclude that one fifth of children aged 6-23 months presented ARI complications, and PCV10 immunization is independently associated with lower odds of development of AOM. Bird at home and ronchi are risk factors of otitis. Crackles are associated with pneumonia.

\section{Acknowledgements}

We would like to thank members of The Acute Respiratory Infection and Wheeze Study Group Phase I and II who collected data and were medical students at the time of the study data collection: Elaine N. Pacheco, Eliana Silva, Eveline Xavier, Karen S. Miranda, Laíse R. Néri, Patrícia F.C. Silva, Ramon S. Amoedo, Rômulo B. Meneses and Thamirys Marinho.

This study was supported by funding from the Bahia State Agency for Research Funding (FAPESB), in Salvador, Brazil.

Conflict of interest: Authors declare no conflicts of interest for this work.

\section{Appendix A. Supplementary data}

Supplementary data associated with this article can be found, in the online version, at http://dx.doi.org/10.1016/j.vaccine.2016.04. 015 .

\section{References}

[1] Budge PJ, Griffin MR, Edwards KM, Williams JV, Verastegui H, Hartinger $\mathrm{SM}$, et al. A household-based study of acute viral respiratory illnesses in Andean children. Pediatr Infect Dis J 2014;33(5):443-7, http://dx.doi.org/10.1097/INF.0000000000000135.

[2] Nair H, Simoes EA, Rudan I, Gessner BD, Azziz-Baumgartner E, Zhang JS, et al. Global and regional burden of hospital admissions for severe acute lower respiratory infections in young children in 2010: a systematic analysis. Lancet 2013;381:1380-90, http://dx.doi.org/10.1016/S0140-6736 (12)61901-1.

[3] Marcone DN, Ellis A, Videla C, Ekstrom J, Ricarte C, Carballal G, et al. Viral etiology of acute respiratory infections in hospitalized and outpatient children in Buenos Aires, Argentina. Pediatr Infect Dis J 2013;32:105-10, http://dx.doi.org/10.1097/INF.0b013e31827d06f.

[4] Chonmaitree T, Revai K, Grady JJ, Clos A, Patel JA, Nair S, et al. Viral upper respiratory tract infection and otitis media complication in young children. Clin Infect Dis 2008;46:815-23, http://dx.doi.org/10.1086/528685.

[5] Antonova EN, Rycroft CE, Ambrose CS, Heikkinen T, Principi N. Burden of paediatric influenza in Western Europe: a systematic review. BMC Public Health 2012;46:815-23, http://dx.doi.org/10.1186/1471-2458-12-968.

[6] Neuzil KM, Zhu Y, Griffin MR, Edwards KM, Thompson JM, Tollefson SJ, et al. Burden of interpandemic influenza in children younger than 5 years: a 25-year prospective study. J Infect Dis 2002;185(2):147-52, http://dx.doi.org/10.1086/338363.

[7] Heikkinen T, Silvennoinen H, Peltola V, Ziegler T, Vainionpaa R, Vuorinen $\mathrm{T}$, et al. Burden of influenza in children in the community. J Infec Dis 2004;190:1369-73, http://dx.doi.org/10.1086/424527.

[8] Ujunwa F, Ezeonu C. Risk factors for acute respiratory tract infections in underfive children in Enugu Southeast Nigeria. Ann Med Health Sci Res 2014;4:95-9, http://dx.doi.org/10.4103/2141-9248.126610.

[9] Klugman KP, Chien YW, Madhi SA. Pneumococcal pneumonia and influenza: a deadly combination. Vaccine 2009;27:9-14, http://dx.doi.org/10.1016/j.vaccine.2009.06.007.

[10] World Health Organization. Training course on child growth assessment. Geneva: WHO; 2008 [WHO website]. Available at: http://http://whqlibdoc. who.int/publications/2008/9789241595070_A_eng.pdf [accessed 13.07.09].

[11] El-Radhi AS, Barry W. Thermometry in paediatric practice. Arch Dis Child 2006;91:351-6, http://dx.doi.org/10.1136/adc.2005.088831.

[12] World Health Organization. Integrated management of childhood illness chart booklet (WC 503.2). Geneva: WHO; 2008 [WHO website]. Available at: http://whqlibdoc.who.int/publications/2008/9789241597289_eng.pdf [accessed 15.01.09].

[13] Department of Health of the State of Bahia [Secretaria de Saúde do Estado da Bahia]. Introduction of the 10 -valent pneumococcal conjugate vaccine in the basic childhood immunization schedule [Introdução da vacina pneumocócica 10-valente (conjugada) no calendário básico de vacinação da criança]. Salvador, Brazil: Department of Health of the State of Bahia [Secretaria de Saúde do Estado da Bahia]; 2010. http://www.vigilanciaemsaude.ba.gov.br/sites/default/files/ Boletim-Implantação-da-Pneumo-10.pdf [accessed 13.03.14].

[14] Ploin D, Gillet Y, Morfin F, Fouilhoux A, Billaud G, Liberas S, et al. Influenza burden in febrile infants and young children in a pediatric emergency department. Pediatr Infect Dis J 2007;26:142-7, http://dx.doi.org/10.1097/01.inf.0000253062.41648.60.

[15] Homaira N, Luby SP, Petri LS, Vainionpaa WA, Rahman RM, Hossain K, et al. Incidence of respiratory virus-associated pneumonia in urban poor young children of Dhaka, Bangladesh, 2009-2011. PLoS ONE 2012;7(2), http://dx.doi.org/10.1371/journal.pone.0032056. 
[16] Nascimento-Carvalho CM, Souza-Marques HH. Recommendation of the Brazilian Society of Pediatrics for antibiotic therapy in children and adolescents with community-acquired pneumonia. Rev Pan Sal Publica 2004;15(6):380-7.

[17] Hazir T, Nisar YB, Qazi SA, Khan SF, Raza M, Zameer S, et al. Chest radiography in children aged 2-59 months diagnosed with non-severe pneumonia as defined by World Health Organization: descriptive multicenter study in Pakistan. $\mathrm{Br}$ Med J 2006;333(7569):629, http://dx.doi.org/10.1136/bmj.38915.673322.80 [Epub 21.08.06].

[18] World Factbook. Hospital bed density (beds/1,000 population). Available at: http://www.indexmundi.com/bangladesh/hospital_bed_density.html [accessed 27.11.15].

[19] Winther B, Hayden FG, Arruda E, Dutkowski R, Penelope Ward P, Hendley JO. Viral respiratory infection in schoolchildren: effects on middle ear pressure. Pediatrics 2002;109(5):826-32.

[20] Janahi IA, Bener A, Wahab AA. Pet ownership and associated respiratory diseases. Aerobiology 2006;22:305-11, http://dx.doi.org/10.1007/ s10453-006-9044-9.

[21] Mir E, Panjabi C, Shah A. Impact of allergic rhinitis in school going children. Asia Pac Allergy 2012;2(2):93-100, http://dx.doi.org/10.5415/ apallergy.2012.2.2.93.
[22] Afonso ET, Minamisava R, Bierrenbach AL, Escalante JJ, Alencar AP, Domingues $C M$, et al. Effect of 10-valent pneumococcal vaccine on pneumonia among children, Brazil. Emerg Infect Dis 2013;19:589-97, http://dx.doi.org/10.3201/eid1904.121198.

[23] Klugman KP, Madhi SA. Pneumococcal vaccines and flu preparedness. Science 2007;316:49, http://dx.doi.org/10.1126/science.316.5821.49c.

[24] Fortanier AC, Venekamp RP, Boonacker CW, Hak E, Schilder AG, Sanders EA, Damoiseaux RA. Pneumococcal conjugate vacines for preventing otitis media. Cochrane Database Syst Rev 2014;4:CD001480, http://dx.doi.org/10.1002/14651858,CD001480.pub4.

[25] Komakhidze T, Hoestlandt C, Dolakidze T, Shakhnazarova M, Chlikadze $\mathrm{R}$, Kopaleishvili $\mathrm{N}$, et al. Cost-effectiveness of pneumococcal conjugate vaccination in Georgia. Vaccine 2015;33(Suppl. 1):A219-26, http://dx.doi.org/10.1016/j.vaccine.2014.12.070.

[26] Palmu AA, Jokinen J, Nieminen H, Rinta-Kokko H, Ruokokoski E, Puumalainen $\mathrm{T}$, et al. Effectiveness of the 10 -valent pneumococcal conjugate vaccine against tympanostomy tube placements in a cluster-randomized trial. Pediatr Infect Dis J 2015, http://dx.doi.org/10.1097/INF.0000000000000857. 